\title{
EINOPOLIIIICA MEXICOAMERICANA EN HOUSTON Y NUEVOS INMIGRADOS
}

\author{
Iban Trapaga* \\ Universidad Autónoma Metropolitana - México
}

Resumen: Aunque el término etnopolítica ha sido aplicado a grupos minoritarios o con un ascendente socio-histórico diferente del nacional hegemónico, en este artículo procuro establecer los parámetros generales y efectos de la etnopolítica mexico-americana sobre los nuevos inmigrados al sureste de Houston en un periodo reciente: 2010-2011. Los corolarios de esta política de minoría étnico-nacional influyen en los modos de recibir, educar y disciplinar a los nuevos inmigrados a la ciudad texana. La etnografía, óptimo instrumento cientifico enfocado a pequeñas comunidades urbanas y a la interculturalidad, nos muestra una realidad muy diferente respecto a la apariencia y discurso emitido por estas organizaciones etno-politicas. Como primera lectura, se comprueban los vínculos estructurales entre la etnopolítica mexico-americana y la ideología nacionalista estadounidense y su proyecto de nación "multicultural”.

Palabras clave: ciudadanía, migración internacional, minorías étnicas, subjetivación.

\begin{abstract}
Although the concept "ethnopolitics" has been applied to ethno-political minority groups or with a different socio-historical origin from the hegemonic nationalism, in this article I try to set the general parameters the Mexico Americans' ethnopolicy in southeast Houston for a recent time: 2010-2011. The corollary of this policy some of ethno-national minorities influence the ways of "welcoming", teaching and disciplining the new immigrants to this texan town. Ethnography, an optimal scientific instrument focused on small urban communities and multiculturalism, shows a very different reality regarding appearance and speech broadcasted by those ethno-political organizations. In my findings, I stablish the structural links between the Mexican American ethnopolicies and U.S. nationalist ideology and its "multicultural" nation's draft.
\end{abstract}

Keywords: citizenship, ethnic minorities, international migration, subjectivation.

\footnotetext{
*Contacto: iban.trapaga@gmail.com
} 


\section{Introducción}

Basada en un trabajo de campo etnográfico desarrollado durante seis meses en barrios hispanos de Houston, presento aquí unos resultados preliminares sobre la conformación de agrupaciones etnopolíticas mexicanas en su relación con los nuevos inmigrados, procedentes estos últimos del norte de México (Tamaulipas, San Luis Potosí, Durango y Coahuila). El trabajo de campo se efectuó entre los meses de octubre a marzo del 2010 y formó parte de una investigación diseñada para implementarse en los barrios históricos del Eastside houstoniano.

Las agrupaciones, formales e informales, representadas aquí por el Chicano Center y presentes en estas áreas favorecen la integración de los inmigrantes recién llegados a la ciudad petrolera. Sin embargo, estos nuevos residentes también manifiestan cierto distanciamiento de sus anfitriones mexico-americanos del $C h C$ y del mismo barrio, creándose fracturas afectivas y culturales entre ambos sectores. Además, las redes sociales de los barrios son diversas, cuando no complejas. Es entonces una integración diferencial donde priman las redes familiares y paisanaje sobre las redes para-institucionales dominadas por agentes nacionalistas estadounidenses, tal y como se hace comprensible más adelante. ${ }^{1}$ En las próximas páginas discutiré la condición étnica de estos grupos, así como la dialéctica desarrollada entre asimilacionistas mexico-americanos y la resistencia pasiva de los neo-residentes. Dentro de esta dinámica de oposición y diferenciación, me concentraré en la descripción y análisis de las instituciones de atención a migrantes que implementan programas de reeducación destinados a la reproducción de estatus étnico-social hegemónico en Estados Unidos.

En una primera exposición, acercaré al lector a los conceptos y técnicas de estudio que crearon la posibilidad y las condiciones de lo aquí estudiado. A continuación, dirigiré mis esfuerzos descriptivos hacia la comprensión del contexto social que convive y permite la existencia del centro comunitario en cuestión. Los últimos apartados están dedicados a la descripción y análisis de las prácticas y discursos de trabajadores sociales, profesorado

1 Por red para-institucional me refiero a las relaciones sociales establecidas en torno o, incluso, subsumidas a agencias de la sociedad civil, como es el caso de los diversos Centers. 
y administradores frente a la resistencia y discursos de los usuarios para terminar con unas primeras reflexiones sobre este tema no abordado aún por la antropología mexicana.

\section{De etnias, minorías étnicas y etnopolítica}

La relación conceptual de la tríada etnia, nación y estado ha supuesto desde su explicitación conceptual una combinación polémica, aunque por causas principalmente políticas. Etnia refiere por lo común a una instancia pre-moderna en tanto consideremos al estado nacional como el actor fundador de la modernidad, y a esta como representación polifacética del capitalismo industrial noratlántico. Es tan resbaladizo el devenir entre una y otra categoría que bien pudiera interpretarse en no pocas ocasiones a los grupos étnicos como naciones sin estado, y a la nación constituyente y constituida de cualquier estado en particular como una etnia históricamente hegemónica que ha transferido sus atributos culturales para la edificación de la ideología nacionalista garante del aparato estatal. Atendiendo esta faceta de la tríada arriba referida es como planteamos la interacción entre las naciones y sus así llamadas minorías étnicas, ${ }^{2}$ donde las últimas se encuentran subsumidas, mayormente dominadas, bajo la panoplia ideológica del nacionalismo de turno. Esta construcción de las naciones modernas ha facturado casos paradójicos como el de Bolivia o Guatemala, naciones cuyas minorias étnicas nativas rebasan numéricamente a su contraparte hegemónica. También en México, donde encontramos decenas de grupos indígenas y afro-descendientes, o en Estados Unidos con sus considerables minorías étnicas procedentes de la migración y de su diezmada población aborigen nos enfrentamos a paradójicas situaciones solo comprensibles desde la ingeniería ideológica que dotó de empaque a estas formaciones históricas recientes.

\footnotetext{
Soy consciente del sesgo ideológico del término ya que, de principio, este concepto es producto de la perspectiva nacionalista de los estados modernos. Como la teoría política ha desarrollado suficientemente, la legitimidad de los estados recae sobre la comunidad imaginada de la nación homogénea, lingüística, religiosa o culturalmente. La minoría no se corresponde pues a un número, sino a una posición subalterna definida por su "carencia" (más que diferencia) socio-cultural. Lo uso aquí en aras de facilitar la comunicación.
} 
Precisamente, son México y Estados Unidos las formaciones nacionales contexto del contenido del presente documento. Por una parte, la nación mexicana debiera considerarse como una nación multiétnica dada su riqueza cultural interna (alrededor de cincuenta grupos étnicos indígenas y afro-descendientes, amén de la suma de pequeños grupos inmigrados como chinos, sirio-libaneses, españoles, la diáspora judía, etcétera.); por otra parte, Estados Unidos, "país de inmigrantes" y del melting polt, ha minorizado estos contingentes inmigrados o conquistados (nativo-americanos, mexico-americanos) etnificando la diferencia social. La ciencia estadística amén de otras tantas más ha elaborado una clasificación étnica pivotando sobre el eje del modelo $W A S P^{3}$ como patrón étnico nacional. Así, los mexicanos migrados a la Unión Americana son transformados de nacionales en minoría étnica apenas traspasan la frontera.

Para Stavenhagen (1991, p. 3), los grupos étnicos o etnias refieren a:

[...] colectividad que se identifica a sí misma y que es identificada por los demás conforme a criterios étnicos, es decir, en función a ciertos elementos comunes tales como el idioma, la religión, la tribu, la nacionalidad o la raza, o una combinación de estos elementos, y que comparte un sentimiento común de identidad con otros miembros del grupo.[...] Los grupos étnicos así definidos, también pueden ser considerados como pueblos, naciones, nacionalidades, minorías, tribus o comunidades, según los distintos contextos y circunstancias.

Como señala el autor son "los distintos contextos y circunstancias" quienes determinan la nominalización del grupo atendiendo a elementos comunes como puede ser el idioma y es esta nominalización y elementos comunes los materiales simbólicos de la identificación externa (fuente de la identidad como producto). Estamos ante el caso de los nacionales mexicanos ${ }^{4}$ en Houston y, por extensión, en todo Estados Unidos, aunque puedan en ocasiones ser subsumidos en otras categorías como hispanos o latinos. En la misma línea, se expresa el marco teórico planteado desde los estudios culturales de la escuela

\footnotetext{
WASP, acrónimo de White Anglo Saxon Protestant representa al núcleo socio-económico de élite fundador del estado-nación estadounidense y su proyecto económico: el capitalismo moderno. Fuera de esta identificación del "americano original" quedan tanto otros europeos (católicos, eslavos, etcétera) como mexicanos, asiáticos, y demás "minorías étnicas”.

4 Este término procede del sistema clasificatorio emanado de los aparatos ideológicos del estado mexicano y está extendido entre la población socializada bajo ese régimen.
}

Horizontes Antropológicos, Porto Alegre, ano 22, n. 46, p. 219-241, jul./dez. 2016 
de Birmingham sobre las identidades culturales, nicho de etnicidad y nacionalismo. Stuart Hall y Paul DuGay (2003) plantean la identificación como concepto central en los estudios de las identidades sociales. Podríamos plantear, entonces, una identidad como producto y una identificación -tanto exógena como endógena, pero siempre interactiva- como functor ${ }^{5} \mathrm{o}$ inductor de las identidades. Este juego identidad-identificación está explícito en la teoría propuesta y desarrollada por Barth (1976) en su secular compilación sobre las fronteras étnicas. En definitiva, y sin ánimo de extenderme más al respecto, las identidades étnicas o nacionales son situacionales -dependen de las situaciones espacio-temporales-y por ende cambiantes, amén de muy dependientes de factores externos al grupo.

Para continuar con esta rápida introducción a los fundamentos conceptuales de este documento, haré alusión a la noción de etnopolítica como categoría empleada en la antropología y las ciencias políticas para englobar fenómenos sociales recientes cuya forma y estructura interna amén de sus reclamos están basados mayormente en cuestiones étnicas, es decir, enarbolan las diferencias culturales e identitarias para conformarse en sujetos sociales emergentes. Bartolomé (1996, p. 4) dirá que son "afirmaciones protagónicas de la etnicidad [...] orientadas hacia la defensa de los intereses étnicos."

Un enunciado desarrollado sobre este planteamiento lo dará Barabas (2008, p. 211-212) al afirmar que:

Estos movimientos políticos seculares [...] que se valen de ideologías y estrategias secularizadas [...] Los movimientos etnopolíticos se expresan usualmente a través de organizaciones civiles, asociaciones voluntarias formadas por lo que llamaríamos grupos de interés, dentro de la comunidad, de la ciudad, o de un grupo de comunidades. Estas organizaciones convocan miembros a partir de la pertenencia étnica y los objetivos de reivindicación etnocultural e intentan relacionarse con el estado o con otras instituciones mediante lógicas negociadoras. Se han clasificado diversos tipos de acuerdo, por ejemplo, con las funciones centrales del movimiento: cooperativas económicas, artesanales o grupos de autoridades, de maestros, grupos activadores de la cultura o la lengua, etc....

\footnotetext{
5 Término tomado de la Teoría de las categorías en matemáticas. Es una adapatación de la categoría kantiana pero indicando las relaciones o funciones entre universos categoriales, más que buscar la identidad en elementos constituyentes y pertenencia.
} 
Podemos hacer un ejercicio de traslación conceptual y retomar al movimiento por los Derechos Civiles en Estados Unidos como un movimiento social constituido sobre la etnicidad ya que fueron las minorias raciales de aquel país quienes protagonizaron una emergencia política basada en la diferencia étnica o nacional, valiéndose de un lenguaje o discurso "político-secular", aunque originado en comunidades religiosas de base que llevaron la cuestión racial, es decir, étnica, a la defensa de sus intereses colectivos. En Houston, y en el Eastside de esta ciudad portuaria en particular, los resabios históricos de este amplio movimiento constituyeron diversas organizaciones mexico-americanas de defensa de la comunidad étnica y barrial, entre ellas emergió y persiste como producto contemporáneo el Chicano Center (ChC), objeto y escenario de esta investigación. Las categorías identitarias vertidas en este texto en ocasiones refieren al mismo grupo o engloban a varios grupos. En el caso de la serie mexico-americano, chicano, tejano, son categorías del mismo grupo pero con sesgos políticos que denotan el citado juego identidad-identificación. Mientras que mexico-americano es el concepto oficial (del censo estadounidense y de otras agencias oficiales) y es usado por sus integrantes dependiendo del contexto, chicano y tejano serían términos endógenos con el matiz en el segundo de ellos de mexicanos desde antes de la conquista estadounidense.

\section{Metodología}

El método etnográfico puede considerarse como el marco de producción de los sujetos antropológicos. Existe un consenso académico para emplazar a la etnografía como alma mater de la antropología moderna y contemporánea, casi definitoria de la disciplina, aunque no exclusiva de la misma (Ferrándiz Martín, 2011, p. 27-39). Una de las peculiaridades de este método y su disciplina afín es su circunscripción micro-social de fenómenos y procesos más amplios (regionales, nacionales y mundiales). Simplificando las palabras, diríamos que los antropólogos estudiamos menudencias cotidianas escenificadas en terruños ajenos, considerando fenómenos sociales amplios o, como señaló Geertz (1996, p. 33), se estudia "en aldeas, no aldeas".

Esta mirada microscópica, amén del recurso reiterado a técnicas más cualitativas que cuantitativas, ha llevado a criticar a la Antropología su incapacidad para generar estudios y análisis que nos conduzcan a objetos de estudio

Horizontes Antropológicos, Porto Alegre, ano 22, n. 46, p. 219-241, jul./dez. 2016 
generales. Incluso muchos colegas sociólogos y afines consideran los métodos cualitativos, en el mejor de los casos, como funcionalmente exploratorios de cuestiones aún no planteadas entre las hipótesis explicativas de algún fenómeno o grupo de tales. Sin embargo, la antropología -ciencia del ser humanoinstrumenta esta panoplia metodológica de sesgo marcadamente cualitativo hacia la comprensión holística del ser humano, que desde una exploración de la alteridad u otredad perfile un conocimiento introspectivo del sí mismo colectivo e individual (Krotz, 2002). El método central para este vasto fin es la intersubjetividad, indispensable en la aplicación de técnicas cualitativas como la observación participante, la entrevista, la biografía, etcétera. En definitiva, la materia prima del análisis etnográfico lo suponen básicamente cuestiones subjetivas, y la comprensión de los sujetos que se consigue mediante la comprensión de sus esquemas sociales interiorizados -formas culturales- es el objetivo epistemológico (Ferrándiz Martín, 2011). Para ello se requieren de altas dosis de extrañamiento, reeducación, interpretación, contextualización y contraste.

Aunque para los fines que aquí nos ocupan, es suficiente con esta acotación y con la relación de técnicas, campo de estudio y condiciones del mismo que sirvieron como cantera para la descripción y análisis aquí vertidos. El trabajo de campo etnográfico se desarrolló durante cerca de seis meses en una zona hispana del oriente houstoniano, relativamente cerca de su centro histórico. Este trabajo etnográfico estuvo enmarcado en el proyecto de investigación de doctorado que plantea una etnografía comparativa de las pandillas mexicanas. Durante el estudio del contexto social y discursivo de las pandillas de Houston oriental fue posible extraer suficientes trazos y datos para conocer mejor -antropológicamente- ese terruño ajeno y cotidiano de los mexico-americanos y mexicanos en este escenario de investigación. Así, durante la etnografía de las instituciones locales participé como alumno de medio tiempo del programa ESL y durante el lapso de tres meses en el ahora objeto de estudio: el Chicano Center.

En ese periodo desarrollé una subrepticia labor basada en la observación participante, así como de entrevistas formales y una encuesta realizadas a compañeros del curso -mayormente mujeres mexicanas vecinas de la zona-, todas ellas en el exterior del centro lejos de las obligaciones escolares. El rango aplicable en cada caso del consentimiento informado de las etnografías es variable y discutido, tanto como discutible (Ferrándiz Martín, 2011, p. 72-73). 
En mi caso, solo dos responsables administrativos del centro fueron informados de mis intereses, así como una parte considerable de compañeras y compañeros de clases. Sin embargo, resultó difícil clarificarles mi tipo de trabajo y los objetivos, siendo confundido en ocasiones por un policía de migración (ICE), o simplemente un personaje presuntuoso. Pero para la mayor parte de los trabajadores de la institución era un usuario más. De este modo, asistí a tantas iniciativas, conferencias y asesorías como me fue posible. ${ }^{6}$ De este modo conocí casi todas las áreas de acción del centro. En el mismo periodo recibimos cuatro sesiones colectivas y forzosas sobre la erradicación de la violencia de género. La primera de ellas, al menos, me sirvió como técnica de grupo focal. Las asesorías de salud (prevención de SIDA, educación sexual, higiene...) fungieron como entrevistas informales a profundidad que, insisto, subrepticiamente apliqué a los trabajadores y voluntarios sociales que las realizaron. De igual modo me conducí durante las escasas comunicaciones informales con el personal administrativo y directivo. En suma, tejí una etnografía paralela sobre el sistema normativo de esta institución local, y sobre el modo de usarlo y pensarlo de sus usuarios. Mi rol como estudiante vecino de la misma colonia ayudó sobremanera, y finalmente el presente escrito debería reflejar la comprensión analítica de este pequeño mundo de las instituciones benéficas para migrantes. ${ }^{7}$

\section{El barrio hispano: tributario del Chicano Center}

El Mango Park -o "Los Mangos" como aún se escucha entre los parroquianos de los antros portuarios- está ubicado en el extremo oriental del llamado Eastside de Houston. Acostado sobre la autopista a la ciudad de Galveston, este sector urbano colinda con varios municipios pertenecientes a la mancha urbana: Jacinto City y Pasadena -popularmente conocida como Stinkydena o

\footnotetext{
6 Este centro reunía en sus dos programas educativos cerca de cien alumnas y alumnos, a razón de quince a veinte por grupo. Los usuarios de otros servicios, como el del banco de alimentos, superaban en ocasiones los 500 solicitantes diarios. Una parte del personal era de planta (administrativos, trabajadores sociales y profesores) sumando de doce a quince personas, y otra parte del personal atendía varios centros asistenciales o comunitarios, patrocinados por una empresa u otra ONG externa al centro.

7 Existen otros estudios sobre centros de beneficencia para migrantes, en concreto un artículo propio sobre la "Casa del Migrante" ubicada en Ciudad Juárez y de cuyo estudio los resultados preliminares han sido publicados en la colección "Chihuahua Hoy".
}

Horizontes Antropológicos, Porto Alegre, ano 22, n. 46, p. 219-241, jul./dez. 2016 
Apestadena-, que concentran las instalaciones de la potente industria petro-química texana. Siguiendo ese mismo derrotero también se encuentra el Sitio Histórico de la Batalla de San Jacinto, parteaguas de la República de Texas.

Aunque se extinguió administrativamente un siglo atrás, el Eastside permanece firme entre las conciencias locales y la memoria colectiva heredada. Este barrio simula un triángulo isósceles imaginario que partiendo del downtown abre sus ángulos hacia el nororiente y el suroriente, límites marcados por sendas autopistas principales. Al oriente, se erigen los municipios de Pasadena y Jacinto City como confines municipales. Todos ellos, en cambio, pertenecen al condado más populoso de Texas, el Condado de Harris, elevando a la ciudad de Houston al cuarto lugar nacional en número de residentes. Toda la superficie que ocupa el Segundo Barrio o Second Ward se corresponde a la llanura pluvial costera, por lo que carece de accidentes orográficos. En la base del triángulo discurre de nororiente a oriente el canal portuario al que confluyen varios arroyos y riachuelos de esta sub-cuenca hidrográfica conocidos como bayous. Así, el Cibola Bayou al norte y el Aryan Bayou hacia el límite meridional, circundan y atraviesan la zona residencial urbana del Segundo Barrio. Es de comprender, por lo tanto, el carácter lodoso de los terrenos adyacentes al puerto.

Históricamente, Mango Park fue un espacio de colonización reciente respecto al Barrio y al área denominada el East End. Mientras que los confines cercanos al downtown fueron ocupados tanto por peones de múltiples orígenes étnicos como por una parte de la élite local procedente en gran número de la burguesía comercial de la costa este norteamericana (McWhorter, 2011). Sin embargo, y desde 1836 y hasta terminar el siglo diecinueve, la expansión urbana sobre este área mantiene un patrón similar a lo largo del tiempo: inversiones de agentes de bienes raíces, hacendados y comerciantes que tras varias décadas de trabajos para establecer condiciones de habitabilidad parcelan sus propiedades para dedicarlas a partir de 1850 a zona residencial, o, más tarde, a la primera industrialización local. También es precoz la presencia de líneas ferrocarrileras en la zona, así como inversiones para habilitar el canal de navegación para buques de mayor calado que fomentarían un auge en el tráfico naviero. Este desarrollo urbano fue acompañado de nuevos contingentes de inmigrantes principalmente de origen germánico. En este momento, el East End establece los cimientos de una zona históricamente poblada por inmigrantes nacionales (tejanos) y extranjeros caracterizados por su origen nacional (mexicanos, centroamericanos). En el caso de los mexicanos, hay 
que considerar que el estado de Texas se ha mantenido históricamente como el segundo, detrás de California, en el número de población mexicana. Esto es, Texas y su cororalio el East End de Houston, son destino principal de la inmigración mexicana a Estados Unidos.

Para 1912, este área de inmigración es transformada en colonia residencial, abandonando los fines lúdicos precedentes. En 1926 fue anexada a la ciudad de Houston y renombrada definitivamente como Mango Park.

Respecto a la evolución demográfica, durante el siglo XIX cabe destacar que no es hasta los albores de la Revolución Mexicana (1910-20) que Mango Park llama la atención de pobladores mexicanos y mexico-americanos. A lo largo de todo el siglo XIX, el grupo nacional dominante en el Segundo Barrio es el austro-germano, con un $40 \%$ aproximado de los residentes, mientras que la población mexicana apenas alcanzaba un 7\% (McWhorter, 2011, p. 40). En rangos generales, Eastside en 1860 supone la quinta parte de la población total houstoniana y ya se consolidaba como el área de recepción de inmigrantes, ya que más de la mitad (53\%) de sus residentes censados eran recién llegados. Es tal el ascendente foráneo que un actor social minoritario en Estados Unidos -la Iglesia católica- se instala en el sector en dos tiempos, señalados por la inauguración de templos: San Valente (1841), y la Anunciación (1871). Décadas más tarde, acorde con los cambios étnico-demográficos, se fundará el templo de Nuestra Señora de Loreto (1911), a la que seguirá la Concepción y otras más. Las iglesias habían llegado para quedarse, erigiéndose en la principal institución social formal hasta la fecha.

La situación se repite hasta pasada esa década primisecular. Mango Park, como colonia durante la última década decimonónica, es ocupada y usufructuada lúdicamente por contingentes alemanes que aún seguían fluyendo hacia Texas. Habían articulado una densa red de organizaciones étnicas que suponían su tarjeta de presentación ante la sociedad local y fungían como redes de apoyo a su paisanaje. Solo a partir del exilio derivado de la Revolución Mexicana es como Mango Park se irá constituyendo como un enclave étnico hispano, predominantemente mexicano. Los primeros asentamientos de mexicanos de clase obrera en la vieja colonia centro-europea de Mango Park procedían mayormente del noreste de México (los ya referidos estados de Tamaulipas, Nuevo León, San Luis Potosí y Coahuila) y de las agencias de contratación radicadas en San Antonio, Texas. La industrialización de la zona se había iniciado exactamente en 1897, con el establecimiento de la Houston 
Tracking Company que compró varias propiedades de germano-americanos para ubicarse cerca del actual Mango Park.

La historia de los mexico-americanos en Houston, aunque de larga data -Lorenzo de Zavala, el liberal yucateco que luchó junto a Sam Houston por la independencia texana, amén de otros méxico-tejanos- carece de peso demográfico hasta la arriba citada primera industrialización y desarrollo de las comunicaciones portuarias y de ferrocarril. Desde San Antonio se enrolan familias completas de mexico-americanos viejos o tejanos $^{8}$ para servir en la estiba portuaria, la apertura de vías de ferrocarril, confección de textiles y calzado, y en la restauración (León, 1989). De 2000 personas de origen mexicano en 1910 para todo Houston (2,54\%) se pasó a 1.671 .540 de individuos de origen hispano exactamente un siglo después (US Census Bureau, 2010). De este millón y medio largo, 710.000 aproximadamente habían nacido fuera de Estados Unidos. ${ }^{9}$ Esto es, los hispanos en Houston constituyen actualmente el $41 \%$ de la población metropolitana local, porcentaje que se incrementa arriba de un $90 \%$ en Mango Park debido al constante arribo de mexicanos y centroamericanos al sector.

Aunque las actividades económicas pivotaron durante décadas sobre la industria del entretenimiento ilegal o inmoral -juegos de azar o geimboleo, prostitución, y consumo de drogas lícitas e ilícitas- equiparando al grupo étnico con este nicho económico, los últimos años presenciaron una clara decadencia de los establecimientos dedicados a este capitalismo de rapiña (Wacquant, 2000), más por su legalización parcial y el traslado hacia otros puntos céntricos que por la acción de la sociedad civil.

Rodríguez et al. (1994) afirman que no es sino hasta mediados del siglo pasado que Mango Park sufre un marcado declive de su vida comunitaria para derivar hacia un modelo de inner city. Pero no solo experimenta una depauperización económica, deterioro urbanístico y patrimonial, y estigmatización

\footnotetext{
8 Mexicanos establecidos antes de la independencia de Texas. El término tejano está dotado de fuerte carga étnica.

9 Según el U.S. Bureau of the Census, 2006-2008 American Community Survey el número de residentes el Greater Houston nacidos en el extranjero oscila alrededor de 1.200.000 repartidos en diferentes orígenes nacionales. Así, el grupo nacional mayoritario lo constituyen los nacidos en México (578.000 [48,3\%]), El Salvador (96.000), Vietnam (60.500), India (45.100), China (44.200), Honduras (41.300), Filipinas (26.100), Guatemala (25.900), Colombia (22.100), Pakistan (21.100), Canadá (14.000), Corea (10.200) e Irán (6.600).
}

Horizontes Antropológicos, Porto Alegre, ano 22, n. 46, p. 219-241, jul./dez. 2016 
social; realmente, Mango Park en particular, y el Second Ward en general, intensificaron la opción pre-existente de ofertar servicios inmorales de diversión y esparcimiento. Aún hoy, la trama urbana aparece salpicada de congales ${ }^{10}$ por doquier, añejos y noveles, decadentes y rentables. La "economía de Casino" se ha mantenido en paralelo al lento pero sostenido declive del modelo industrial fordista hegemónico en la zona. Así, complejos fabriles asentados en la zona como la Nabisco, Co. resintieron la implantación del modelo neoliberal, trasladando la producción del puerto al ultramar asiático o latinoamericano. Durante décadas, este modelo industrial exportador concentrado en la zona portuaria caracterizó la economía y, por ende, la fisonomía urbana local. Actualmente, Mango Park y adyacentes exhiben un paisaje de segunda industrialización, con escasa terciarización excepto por la retícula de congales, negocios étnicos, edificios gubernamentales, de organizaciones no gubernamentales y de la sociedad civil y zonas residenciales de bajos ingresos.

Junto a los servicios ilícitos, que persisten también en el ámbito privado de los domicilios, el ámbito público exhibe una galería donde predominan los servicios principalmente de índole social y jurídica, alimentaria, de transporte y una hipérbole de oferta espiritual representada por tres templos católicos, ocho protestantes, decenas de "centros espirituales" donde se ofrecen servicios de limpias, adivinación, y otros "trabajos" con materias. ${ }^{11}$

\section{Chicano Center, enrolando a inmigrantes hispanos recién llegados}

El popularmente conocido como Parque Mexicano donde se exhibe una escultura de Miguel Hidalgo esencializa la conformación demográfica de este colonia lindante y subsidiaria laboral y económicamente del Puerto de Houston. Como planteaba arriba, desde el primer asentamiento en la década de 1920 Mangos Park ha representado un apéndice de México en Houston. Aunque actualmente la mayor parte de la población es mexico-americana o,

\footnotetext{
${ }^{10}$ Los así llamados no son sino prostíbulos, pero un modelo mexicano norteño "tradicional". Esto es, dirigido a segmentos de población culturalmente tradicionales y de bajos ingresos. Por su carácter tradicional, los usuarios raramente cuentan con menos de 30 años, extendiéndose hasta octogenarios. Así, la baja inversión, calidad de oferta, cuota de beneficios e inversión son limitadas, el modelo empresarial es individual o familiar en ocasiones interrelacionado con base a redes informales. En general, y expresado así por fines sintéticos, se trata del modelo propio de las "zonas de tolerancia".

11 Individuos que operan como mediadores entre el mundo físico y el espiritual. Sinónimo de médium.
}

Horizontes Antropológicos, Porto Alegre, ano 22, n. 46, p. 219-241, jul./dez. 2016 
como ellos gustan decirse, tejana, también existen grupos númericamente notables de mexicanos y centroamericanos, junto a incipientes grupos de afro-americanos. De hecho, la constitución poblacional está fundamentada en el recambio migratorio protagonizado por las segundas y terceras generaciones de sucesivos contingentes inmigrados originarios de los estados mexicanos ya referidos arriba.

La citada dualidad étnico-nacional se erige como cualidad de existencia de la vida comunitaria. Cabe resaltar que esta es una situación común al conjunto estatal texano y no una particularidad local, tal y como queda patente en varias obras (Castellanos Guerrero, 1981; León, 1989; Richardson, 1999), aunque con matices en sus enfoques. Así, Castellanos Guerrero (1981, p. 200) asentará en la que fue su primera obra con respecto al ascendente que asumen los mexico-americanos sobre otros grupos de origen mexicano:

[...] La discriminación en contra de los mexicanos, aunque en un grado mucho menor, es también ejercida por algunos sectores de la población chicana de los Estado Unidos [...] Esta situación se vuelve aún más compleja si se considera que la interacción con los chicanos es aún mayor que la que mantienen los mexicanos con los anglos, no solo en los aspectos o vínculos familiares, sino también en la de carácter laboral o comercial[...] en muchas ocasiones son chicanos los 'capataces' de los mexicanos que trabajan en Estados Unidos y 'casualmente' un número creciente de autoridades de inmigración, del FBI y de la CIA son de origen mexicano. Algunos de los trabajadores que han laborado en los Estados Unidos expresan las contradicciones existentes en el interior de la clase trabajadora en ese país, al afirmar que en ocasiones recibían un trato peor de los chicanos [...].

Mientras que Richardson desgrana las oposiciones identitarias y estereotipos desarrollados entre mexicanos y mexico-americanos, para demostrar el alto grado de inserción -aculturación- en la sociedad estadounidense de la mayoría de esta minoría étnica. León no se queda atrás, y describe el principio de la ruptura entre ambas comunidades en Houston a partir de la década de la segunda posguerra mundial. Caso sintomático -afirmará León (1989, p. 153154)- son las relaciones con el Consulado de México en Houston:

Indeed, it was the very meaning of the commemorations which in September 1973 produced a clash beween what the Mexican American community thought the fiestas patrias to be, and what the Mexican consul undeerstood them 
traditionally to symbolize. [...] For Fiestas Patrias leaders, the commemorations represented a well-established project, expanded upon during the 1960's when a comité patriótico ceased to function.[...] But the occasion served as an example of the continued americanization of the Mexican community which simultaneously preferred allegiance to the United States while stubbornly paying its respect to its Mexicanness. ${ }^{12}$

Más allá del desencuentro político entre ambas comunidades o proyectos, la aquí descrita resistencia cultural de la comunidad chicana fue el parte aguas de la lucha activa por los derechos civiles de chicanos y mexico-americanos en general que derivó en las décadas posteriores a 1960 en la mayor efervescencia organizativa de este grupo étnico estadounidense, conformándose entre 1960 y 1975 -inicio de la decadencia del movimiento- los diversos "centers" del chicanismo local, que parecen provenir del crisol de organizaciones. La apuesta por la educación, la mejora económica de la Raza (la comunidad mexicana) se apoyaba mayoritariamente sobre la solicitud y gestión de fondos gubernamentales provinientes de las corrientes liberales del partido demócrata y de sus afiliados mexico-americanos, considerando varios autores ya citados a esta postura como moderada, incluso como conservadora (dentro de la coyuntura), aunque rupturista con la lealtad a Texas como principio de libertades liderada por los LULAC ${ }^{13}$ y sus sucesores. El papel de la Iglesia Católica parece incierto, pero los llamados "conservadores" pro-democratas tenían sus cuarteles en el corazón de Los Mangos, justo dentro de las instalaciones del complejo católico del Corazón de Jesús (León, 1989, p. 163-198).

Por lo tanto, hay que ubicar la fundación en 1972 del $C h C$, ubicando su sede en el corazón del barrio, dentro de esta dinámica postrera de repliegue de los movimientos chicanos por las libertades y el poder político (que incluían

12 Traducción propia: "De hecho, fue la más significativas de las conmemoraciones la que en septiembre de 1973 provocó un choque entre lo que la comunidad mexico-americana pensaba que eran las Fiestas Patrías y cómo el cónsul mexicano entendía que debían ser tradicionalmente simbolizadas. [...] Para los dirigentes de las Fiestas Patrías, las conmemoraciones representaban un proyecto bien establecido, que se extendió hasta la década de 1960 cuando un comité patriótico dejó de funcionar [...]. Pero la ocasión sirvió como un ejemplo de la continua americanización de la comunidad mexicana quien prefirió simultáneamente la adhesión a los Estados Unidos mientras obstinadamente rendía sus respetos a su mexicanidad."

13 Los LULAC son los primigenios o, al menos, más veteranos, clubes de inspiración étnica entre los tejanos de Houston. Es acrónimo de League for United Latin American Citizens. 
dos formaciones partidistas, el Raza Unida Party -RUP- como más importante). Se trataba de grupos de tejanos residentes del barrio, que incluidos los grupos católicos de base estaban participando en el movimiento por los Derechos Civiles o, al menos, se inspiraban en esa lucha pacífica de reivindicación de La Raza. No es un caso aislado y experiencias más o menos institucionalizadas como el Tejano Community Center se hallan en la misma zona. Aunque la adscripción política inicial del $C h C$ es confusa actualmente manifiestan una fuerte tendencia hacia el partido Demócrata y, progresivamente, han pasado de la emergencia y la movilización social hacia una institucionalización etnopolítica con intensas dependencias y labores compartidas con organizaciones no gubernamentales y empresas de carácter social. Aunque la educación como factor de ascenso social subyace a la política social de esta institución, el asistencialismo orientado hacia grupos vulnerables completa el cuadro de programas operados en las cuatro últimas décadas. Así es como encontramos un banco de alimentos, y un servicio médico orientado a los chequeos epidemiológicos entre sus actividades emblemáticas. El personal directivo y de base es mayoritariamente mexico-americano, aunque no faltan otros latinos, algún afro-americano y varios anglo-americanos altruistas y demócratas (miembros del Partido Demócrata) entre sus copartícipes. En este último caso, invariablemente se trata de profesores de lengua inglesa.

La educación impartida para la comunidad hispana del barrio consiste en formación ESL y GED. ${ }^{14}$ En su carta fundacional, el ChC considera que el rezago socio-económico del barrio se origina en la poca o nula aptitud lingüística de una parte considerable de sus residentes. El inglés es la llave de la integración a la nación, y esta última el requisito sine qua non para el progreso económico. Más adelante, plantearé la práctica cotidiana de este principio entre el personal de la institución.

Respecto a otros programas cabe decir que el reparto gratuito de alimentos se realiza todos los viernes. Desde temprano en la mañana, una nutrida formación de residentes, mujeres en su mayoría, se agolpan ante las puertas del establecimiento para tomar su turno. Dos a tres horas más tarde se inicia con la distribución controlada de alimentos frescos y procesados. Es necesario

${ }^{14}$ Cursos de lengua inglesa (English Second Language) y el certificado de preparatoria (General Educational Development test) necesario para demostrar capacidad para ciertos empleos calificados o para acceder a estudios superiores.

Horizontes Antropológicos, Porto Alegre, ano 22, n. 46, p. 219-241, jul./dez. 2016 
un gafete ${ }^{15}$ otorgado después de una evaluación realizada por el personal interino. Otros programas dirigidos específicamente a los usuarios hispanos del Centro son el control y prevención del virus del SIDA, el dirigido a jóvenes criminales y el programa de prevención de la violencia machista.

Mientras que el programa orientado a la rehabilitación de jóvenes infractores pertenecientes a la demarcación urbana del Centro es un proyecto integrado por usuarios tejanos con ciudadanía estadounidense y donde destacan dos grupos: los infractores de normas de tránsito ( $D W I$, conducir bajo efectos del alcohol) y los miembros de pandillas urbanas inculpados por conductas incívicas, los programas de control epidemiológico y de violencia contra las mujeres están dirigidos, en la práctica, hacia los nuevos inmigrados usuarios de los servicios educativos y alimentarios.

Las pláticas privadas con el médico - mexico-americano- del Centro están dirigidas a quien voluntariamente quiera recibirlas. También dispone el Centro de un instructor afro-americano pero este solo atendía a población no hispana. Se efectúan durante las clases o en los recesos de las mismas. La plática informativa se centra tanto en el uso de preservativos como en un sutil cuestionario sobre los prejuicios sexuales y estereotipos del receptor. Así, junto al instructivo sobre el uso del condón y las diferentes enfermedades venéreas la mitad de la asesoría estaba dirigida a cuestionar, debatir y eliminar la presunta homofobia del usuario.

Durante la reunión que sostuve, el experto médico apuntaba continuamente a la normalidad de las relaciones homosexuales. "Porque hay ocasiones que tú vas a los congales, bebes mucho y conoces una persona que tú crees que es mujer pero no hay ningún problema ¿tú sabes? -Sí, te puede gustar igual-, jexactly! es lo mismo, es lo mismo amar a hombres" (Diario de campo, Febrero de 2011). Esta y otras consideraciones fueron parte importante de nuestra conversación, y estimo lícito suponer que se trata de un esquema reiterado entre todos los usuarios, al menos los masculinos. Sin embargo, al tratarse de sesiones de participación voluntaria y por su contenido íntimo pocos eran los usuarios que acudían con este médico. Por el contrario, las pláticas sobre violencia machista se desarrollaban obligatoriamente durante las horas lectivas y se ofrecían solo en lengua española. La animadora socio-cultural era una

15 Porta-credenciales, por metonimia, la identificación o carné expedido por el $C h C$.

Horizontes Antropológicos, Porto Alegre, ano 22, n. 46, p. 219-241, jul./dez. 2016 
mujer nacida en San Luis Potosí (centro de México), y se presentó como integrante de una ONG con visión y misión feminista. Este programa se impartió durante cuatro sesiones. Antes de las pláticas los responsables administrativos del centro nos visitaron advirtiéndonos sobre la obligación de la asistencia. La participación fue motivada continuamente por la oradora experta y se presentaron interesantes situaciones, tan ricas como en un grupo focal, para entender los roles y valores dominantes entre el conjunto de migrantes hispanos residentes en la zona. Junto a los valores tradicionales de la familia, las obligaciones domésticas compartidas, la inclusión plena en el mundo laboral de las mujeres y el respeto a la voz femenina, los partícipes defendían la posición de autoridad del padre de familia y las "buenas costumbres" de las mujeres (madres, hermanas y esposas). La situación excepcional fue provocada ante la defensa de las trabajadoras sexuales efectuada por la oradora: "Ser prostituta no debe ser razón de violencia contra estas mujeres ¿ustedes no lo creen?". La opinión colegiada, de hombres y mujeres, mexicanos y salvadoreños, fue aceptar lo contrario: prostituirse es exponerse voluntariamente a la violencia física, sexual y verbal. El incidente tomó notoriedad ante la intransigencia de la voluntaria feminista, aunque finalmente se impuso el silencio por la autoridad de los administradores presentes pero en el receso, por los pasillos, mientras se reunían los habituales vendedores ambulantes de alimentos -ellos también alumnos del centro-, y ante las mesas del café se formó un intenso rumor cargado de crítica; se habló de imposición y, alguno, expresó su negativa a continuar su asistencia al taller sobre violencia machista. También llovieron críticas de inconformidad referida a otro aspecto: las clases son de ESL (lengua inglesa), por lo tanto usuarios manifestaron que era perder el tiempo asistir a pláticas en español. Muchos de los asistentes trabajaban largas jornadas, incluida la labor doméstica, y resultaba un enorme sacrificio acudir a diario a las clases de cinco horas para que estas no apoyaran el aprendizaje del inglés.

La respuesta del centro no tardó, y un día más tarde amonestaba a una de las voces más críticas con una sanción de dos días sin derecho de asistencia. Se hizo muy patente la presencia de orejas (informantes de la dirección institucional) entre nosotros que informaban puntualmente sobre nuestras "prácticas y discursos"; el grupo mantuvo su asistencia a las sesiones sobre violencia pero ya nunca más hubo participación salvo la derivada de la escucha pasiva.

Es por lo arriba expuesto aún más relevante para los fines de este artículo resaltar la condición de los usuarios del Centro: casi todos ellos provienen de 
México y República del Salvador, junto a otros grupos nacionales centroamericanos; el resto son algunos jóvenes mexico-americanos del barrio, infractores de normas o leyes. Es decir, nos encontramos ante una institución que instrumenta un discurso etnopolítico y ciertas prácticas (como es la orientación hacia poblaciones hispanas indocumentadas) pero cuyo trabajo social se proyecta hacia otros grupos nacionales afines, ya que entran dentro del clúster hispano o latino, tomando cierta dirección cuando no una franca hegemonía sobre estos últimos. Esta hegemonía tiene sus orígenes -según la literatura al respecto- en la década posterior al segundo conflicto mundial, cuando la mayoría de los colonos tejanos optó por integrar una identidad estadounidense rompiendo los lazos con la "Madre Patria Mexicana", excepto por los lazos estrictamente familiares (León, 1989).

Esta prominencia se logra en primera instancia desde la esfera político-jurídica: ciudadanos frente a residentes indocumentados; en segunda instancia, la secesión económico-laboral: asalariados cualificados y estables frente a subempleados y desempleados, incluidos varios jornaleros urbanos; una cesura más que subraya el predominio del grupo directivo es cultural: personal bilingüe con mayor asimilación cultural frente a neófitos monolingües. Tampoco hay que desdeñar la separación entre expertos e inmigrados. La oradora feminista fundamentaba su autoridad (y leve superioridad) sobre la opinión general basándose en su condición de experta estudiosa del tema. Y precisamente es desde esta esfera, la ideológica, simbólica y cultural, donde se instrumentan la mayor parte de los conflictos entre grupos minorizados dirigentes y grupos minorizados subalternos, tal como describiré a continuación.

\section{¿Instituciones de aculturación o de resistencia etnopolítica?}

Desde los primeros pasos, los usuarios de la educación para ESL y GED reciben sucesivas pláticas públicamente y recomendaciones individualmente. La normativa se introduce mediante estas prácticas socio-discursivas y se sanciona con la expulsión del programa. Junto a la normativa austera, diríase victoriana, que proscribe el uso de cierto tipo de ropa y maquillaje para las mujeres, y el de cachuchas, gorros o sombreros para los hombres, o la degustación de chicle también para los hombres, se impone a los neófitos un cuadro de valores cuya adquisición es anunciada como prerrequisito no solo 
para recibir la formación académica sino para el éxito en Estados Unidos. Este fragmento del reglamento interno de "Conducta y Respeto" distribuido al inicio del curso de ESL entre los neófitos admitidos supone una viva estampa de la economía moral dominante en el centro:

[...] los estudiantes deben vestirse de manera apropiada y deben mantener buena higiene personal. Si usted no sigue estas normas de vestir será enviado a su casa. Lo siguiente es considerado inapropiado: Blusas sin mangas, blusas de tirantes, venir en brasier; vestuario que pueda alterar el procedimiento y concentración de los alumnos; blusas, pantalones o faldas cortas. (Folio 1 Manual interno de "Conducta y Respeto", énfasis en el original).

Esta normatividad resume la esencia del nacionalismo cívico anglosajón fundamentado en patrones de convivencia que privatizan las actividades sociales, ensalzan el éxito económico sobre otros aspectos, e inferiorizan parte del legado cultural portado desde México y El Salvador al tratarlo abiertamente como atraso cultural y económico. Así, en las pláticas públicas se aplica recurrentemente el argumento del ¿qué pensarán los americanos si vieran esto o aquello?, referido, por ejemplo, al consumo de la goma de mascar, los restos de esta pegados en el piso o bajo el pupitre. Mientras que en las pláticas privadas, cada uno de los usuarios recibíamos instructivos relacionados con nuestra conducta sexual, nuestras actitudes respecto a las mujeres, sobre el consumo de alcohol y las actividades lúdicas deseables y las reprobables, sancionados todos ellos como "pasos necesarios para ganarse la residencia o la ciudadanía". En suma, bajo el discurso cívico y del éxito económico se introducen fuertes pautas aculturantes con la intención de conformar nuevas subjetividades americanizadas, aunque eso sí, respetando el uso pautado del español.

La respuesta de los usuarios mexicanos se daba gradualmente pero, ante todo, silenciosamente. Al temor de perder los beneficios derivados de esta educación gratuita se unían factores como el control social interno personificado en personal de confianza u orejas reclutados entre los mismos estudiantes; la pérdida de la probatoria -libertad condicional-entre los beneficiados por esta cláusula, todo ello sin menospreciar la fuerza intimidatoria de la misma vergüenza de ser expulsado ante tus propios compañeros.

No obstante, la educación como valor y progreso orilla a mis eventuales compañeros a acudir a diario. Es decir, junto a motivos compulsivos como la pérdida de libertad condicional o la vergüenza de la expulsión, también emana 
del centro educativo una legitimación fundada en la ecuación "educación = progreso", en particular de los estudios en lengua inglesa. Esta idea cohesiona la institución completamente, nadie opina al contrario: "estudiar para no ser delincuentes" - afirma una joven madre soltera-, "estudiar en el $\mathrm{HHC}^{16}$ para sobresalir y progresar" -afirma por otra parte Jessica, paisana duranguense-. En este sentido, el lema del ChC "The Cornerstone of ChC's is Education", coincide con la doxa de los usuarios mexicanos y posibilita el consenso de la dominación.

Más allá de los aspectos positivos, este modelo de micropoder fluye imbricado con formas de control social y simbólico que se manifiesta en una fórmula de economía moral que, mediante el maniqueísmo ético, manipula las conciencias buscando un cambio de conducta. La diversidad o resistencia del pensamiento propio es rápidamente ninguneada, silenciada o reprimida. Aunque este modelo educativo es identificable con otras formas de disciplina católica y cristiana en general, debo recalcar el contexto social y étnico-nacional. El grupo hegemónico del $C h C$ instrumenta un dispositivo de subjetivación (Foucault, 2002) cuyo discurso reproduce la diferencia o estratificación étnico-nacional al interior de la sociedad estadounidense. Las constantes alusiones despectivas a valores incompatibles con respecto al ideal cuerpo cívico-moral estadounidense (homofobia, machismo, violencia, ignorancia) conforman la panoplia discursiva de superioridad cultural, los límites morales entre un ciudadano y un extraño. Además, sutiles alusiones a los ausentes los anglo-americanos-como modelo de comportamiento y superioridad (¿qué pensarán de ustedes los americanos?) uncido a su posición de mando y experiencia (profesorado) intramuros al Centro, no hace sino ratificar la inferioridad -y por ende, la necesidad de cambiar, para "progresar"- de los inmigrados latinoamericanos. La disciplina moldeada por el cristianismo y sus centros de educación está al servicio de la ideología nacional dominante aunque en muchas ocasiones permita elementos y criterios de diversidad, una suerte de "ciudadanía estadounidense en español".

\section{Últimas consideraciones}

${ }^{16}$ Houston Community College. Las Escuelas Comunitarias son una opción de calidad y económica para cursar o acceder a estudios superiores en Estados Unidos.

Horizontes Antropológicos, Porto Alegre, ano 22, n. 46, p. 219-241, jul./dez. 2016 
La lucha etnopolítica de los mexicanos en Houston corre por dos vias: la mexico-americana y la propiamente mexicana. Para estos últimos, los intereses colectivos como minoría nacional o étnica están depositados más en las redes informales de parentesco, de paisanaje y vecinales, que en la acción igualmente etnopolítica de las viejas instituciones tejanas totalmente implicadas en un proyecto nacional estadounidense que, aunque contempla la polietnicidad y multiculturalidad, refuerza el espíritu del nacionalismo preexistente. Las prácticas a que son sometidos los usuarios de estas instituciones deberían recibir no solo la crítica sino una modificación profunda respetuosa con sus etnicidades.

No parece próximo, o posible, un cambio en este modelo de dominación por origen nacional, pero la intervención de las autoridades estadounidenses competentes en las materias implicadas, tanto como la participación consular, mexicana y centroamericana, en este tipo de instituciones para monitorear los contenidos morales implícitos y explícitos se demuestra más que necesario: está en juego la defensa de los derechos ciudadanos y culturales de la población usuaria actual y futura.

Por último, una perspectiva comparada en el estudio de las instituciones de beneficencia para migrantes orquestadas por la Iglesia Católica apunta hacia continuidades o paralelismos en el modelo operativo, más allá de la ubicación geográfica. En Ciudad Juárez (Trapaga, 2012) o en Bangalore, ciudad de la India, (Glockner Fagetti, 2014) se han observado idénticos mecanismos de encierro, disciplinamiento y reeducación de usuarios migrantes en y por instituciones católicas. Asimismo, ciertos prejuicios persisten: malas costumbres, adicciones, homofobia, violencia contra las mujeres... Y la casi absoluta opacidad de estos centros a la mirada externa los hace más autoritarios y en riesgo de transformarse en centros que bajo la égida de los derechos humanos violenten los derechos de sus usuarios. La subjetivación de los migrantes por parte de instituciones históricamente orientadas hacia el control social y sexual orilla a pensar en un dispositivo más amplio, paraestatal, de regulación social en tiempos de vertiginosos cambios inducidos por la condición de la Globalización y el acento neoliberal que delega funciones estatales en grupos privados y religiosos, y que, en el ámbito de la política nacional estadounidense parece apuntar a una resubjetivación de los nuevos inmigrados como la implementación de dispositivos de resubjetivación, re-educación y control orientados, en todo caso, hacia la construcción del modélico buen migrante 
basado en los axiomas de la ciudadanía cívica propia del modelo hegemónico norteamericano.

\section{Referencias}

BARABAS, A. Los derechos indígenas, la antropología jurídica y los movimientos etnopolíticos. Ilha, Florianópolis, v. 10, n. 1, p. 201-216, 2008.

BARTH, F. Los grupos étnicos y sus fronteras. Ciudad de México: FCE, 1976.

BARTOLOMÉ, M. A. Movimientos etnopolíticos y autonomías políticas en México. Brasília: Universidade de Brasília, 1996. (Série Antropologia, 209).

CASTELLANOS GUERRERO, A. Ciudad Juárez: la vida fronteriza. Ciudad de México: Nuestro Tiempo, 1981.

FERRÁNDIZ MARTÍN, F. Etnografias contemporáneas: anclajes, métodos y claves para el futuro. Barcelona: Anthropos-UAMI, 2011.

FOUCAULT, M. La hermeneútica del sujeto. Ciudad de México: FCE, 2002.

GEERTZ, C. La interpretación de las culturas. Barcelona: Gedisa, 1996.

HALL, S.; DUGAY, P. Cuestiones de identidad cultural. Buenos Aires: Amorrortu, 2003.

GLOCKNERFAGETTI,V.Trabajo infantily regimenes de gubernamentalidad: slums flexibles, Ongs, producción de subjetividades en la India contemporánea. 2014. Tesis (Doctorado en Ciencias Antropológicas)-UAM-Iztapalapa, Ciudad de México, 2014.

KROTZ, E. La otredad cultural entre utopía y ciencia: un estudio sobre el origen, el desarrollo y la reorientación de la Antropología. Ciudad de México: FCE: UAMI, 2002.

LEÓN, A. de. Ethnicity in the sunbelt: a history of mexican americans in Houston. Houston: University of Houston, 1989. 
McWHORTER, T. From Das Zweiter to El Segundo, a brief history of Houston's Second Ward. Houston History Magazine, Houston, v. 8, n. 1, p. 38-42, 2011.

RICHARDSON, C. Batos, bolillos, pochos, and pelados: class and culture on the south Texas border. Austin: University of Texas, 1999.

RODRÍGUEZ, N. P. et al. Political mobilization in Houston's Magnolia. In: GARZA, R. O. de la; MENCHACA, M.; DeSIPIO, L. (Ed.). Barrio ballots: Latino politics in the 1990 elections. Boulder: Westview Press, 1994. p. 83114.

STAVENHAGEN, R. Los conflictos étnicos y sus repercusiones en la sociedad internacional. RICS, v. 43, n. 1, 1991. Disponible en: $<\mathrm{http}: / / \mathrm{www}$. cholonautas.edu.pe/modulo/upload/CONFLICTOS\%20ETNICOS.pdf $>$. Acceso en: 5 mayo 2011.

TRAPAGA, I. Instituciones de asistencia a migrantes colonizadas por el discurso securitario. El caso de Ciudad Juárez. Chihuahua Hoy: Visiones de su Historia, Economía, Política y Cultura, v. 9, p. 317-340, 2012.

US CENSUS BUREAU. US Census 2010. Washington DC, 2010. 1 CDROM.

WACQUANT, L. Las cárceles de la miseria. Buenos Aires: Manantial, 2000. 